\title{
Variability in positional, energetic and morphometric descriptors of European anchovy Engraulis encrasicolus schools related to patterns of diurnal vertical migration
}

\author{
K. Tsagarakis ${ }^{1,2, *}$, M. Giannoulaki ${ }^{1}$, S. Somarakis ${ }^{1}$, A. Machias ${ }^{1}$ \\ ${ }^{1}$ Hellenic Center for Marine Research, Former American Base, Gournes, 71003 Heraklion, Greece \\ ${ }^{2}$ Department of Biology, University of Crete, 71409 Heraklion, Greece
}

\begin{abstract}
Acoustic data from summer echo-surveys in the Aegean Sea (Eastern Mediterranean) were analysed in an effort to better understand the mechanisms related to diel vertical migration and the schooling behaviour of European anchovy Engraulis encrasicolus in relation to the time of day. Cosine, quadratic and generalized additive models (GAMs) were used to describe the diurnal patterns in the vertical position and the energetic and morphometric characteristics of anchovy schools. The effect of environmental variables on a suite of school descriptors was additionally examined using GAMs. Disruption of schooling at night was followed by school formation just before dawn at shallow layers, usually above the base of thermocline. Schools moved to deeper depths, close to the seabed during daytime and returned close to the surface to disperse after dusk. Surface light intensity and bottom depth explained a significant amount of variability in the vertical position of schools. Higher light intensities urged schools to deeper depths but maximum downward displacement was constrained by sea bottom in coastal waters $(<80 \mathrm{~m})$. Along with positional changes, diurnal patterns in school shape and packing density were also identified. Morphometric and energetic descriptors were mostly influenced by school altitude (distance from bottom), bottom depth and ambient light intensity. They presented high plasticity that could partly be explained in terms of the trade-off between predator avoidance and feeding success. The effect of schooling behaviour and diel vertical migration should be taken into account in pelagic fish bioenergetic models and in acoustic surveys in respect to sampling design and species discrimination.
\end{abstract}

KEY WORDS: European anchovy $\cdot$ Diurnal vertical migration $\cdot$ School structure $\cdot$ Small pelagic fish $\cdot$ Generalized additive models $\cdot$ Eastern Mediterranean Sea

\section{INTRODUCTION}

Diel vertical migration (DVM) is a common behaviour among small pelagic fish (Blaxter \& Hunter 1982, Fréon \& Misund 1999). Most species migrate downwards after sunset and return to shallow water depths at dusk (Blaxter \& Hunter 1982), though the opposite pattern has also been described (e.g. Zwolinski et al. 2007). Changes concerning the vertical position of schools are followed by changes in school structure especially during dawn and dusk (Fréon et al. 1996). These changes usually lead to school dispersion after dusk (Blaxter \& Hunter 1982, Fernandes et al. 2001, Nilsson et al. 
2003) or to more loose aggregations that may remain overnight (Fréon et al. 1996, Zwolinski et al. 2007).

DVM may affect estimates of fish abundance derived by acoustic methodology as it changes fish availability to the acoustic apparatus and generates difficulties in distinguishing fish from other scatterers (Fréon et al. 1993, Fernandes et al. 2001, Simmonds \& MacLennan 2005). These factors can cause limitations and/or bias in acoustic estimates (Simmonds \& MacLennan 2005). They should be taken into account during survey design or the more coherent concept of 'acoustic populations' should be used (Gerlotto 1993), which describes the entire community and possibly reduces uncertainty in biomass estimates. Moreover, the study of temporal (i.e. diel) evolution of school types can provide important information on the parameters that affect fish behaviour (Paramo et al. 2007). School typology is known to be affected by several factors (e.g. external stimuli, Fréon et al. 1992; vessel noise and environment, Soria et al. 2003; fishery pressure, Castillo \& Robotham 2004; the presence of other species, Massé et al. 1996, Iglesias et al. 2003) in addition to DVM (Fréon et al. 1996, Zwolinski et al. 2007).

Three major hypotheses (foraging, bioenergetics and predator avoidance) have been used to explain the adaptive significance of DVM in pelagic fish. According to these, DVM largely reflects zooplankton (or generally prey) daily movements (foraging hypothesis) and their preferences to specific water temperatures that maximise growth rate (bioenergetics hypothesis) (Levy 1990a, Neverman \& Wurtsbaugh 1994). On the other side, DVM is likely to simply reduce the risk of predation (i.e. predator avoidance; Clark \& Levy 1988, Levy 1990b). However, questions are still open concerning the environmental factors that drive this behaviour and trigger the initiation of downward and upward movements. DVM has been primarily associated with light intensity (Blaxter \& Hunter 1982, Fréon \& Misund 1999, Giannoulaki et al. 1999, Nilsson et al. 2003). Several authors have reported a threshold value in light intensity at which the schools form and disperse (e.g. Blaxter \& Hunter 1982, Nilsson et al. 2003). Beyond this threshold, vertical position may be regulated by levels of luminance (Giannoulaki et al. 1999, Nilsson et al. 2003). Moreover, diel patterns in vertical distribution and associated changes in school size, density and shape may be affected by a multitude of environmental parameters such as temperature stratification (Busch \&
Mehner 2009), substrate type (D'Elia et al. 2009), bottom depth (Johnsen \& Godø 2007, D'Elia et al. 2009), oxygen (Parker-Stetter \& Horne 2009) and oxycline that delimits fish distribution over the top of the oxygen minimum zone (Bertrand et al. 2010), as well as the presence of prey (Bertrand et al. 2008), competitors or predators (Massé et al. 1996).

The European anchovy Engraulis encrasicolus is one of the most important small pelagic fish species both in the Mediterranean Sea (Lleonard \& Maynou 2003, Machias et al. 2008) and off the Atlantic coasts of Europe (Uriarte et al. 1996). However, information regarding its DVM and the mechanisms that control this behaviour is scant. Existing studies mention that anchovy schools rise close to the surface (Masse 1996) and disperse during the night (Iglesias et al. 2003) while during the day they tend to regulate their position according to biotic (e.g. predators and competitors; Massé et al. 1996) and abiotic factors, such as hydrological structures (Masse 1996), substrate type (D'Elia et al. 2009) and bottom depth (Massé et al. 1996, D'Elia et al. 2009). However, the patterns of its vertical movement and schooling behaviour have not yet been examined in the context of the diel cycle or modelled in relation to environmental factors.

In the present paper, we examine aspects of the DVM of anchovy based on acoustic data that were collected in the Aegean Sea (eastern Mediterranean, Greece) during 3 summer acoustic surveys (2004 to 2006). We aim to model the vertical movements of European anchovy schools within the diel cycle and the associated changes in school structure in relation to DVM in relation to the environmental factors that drive them. School formation and dispersion based on the observed number of anchovy schools during the $24 \mathrm{~h}$ period is examined. Diurnal patterns in positional, morphometric and energetic school parameters are described using statistical models. Finally, observed changes are related to specific environmental parameters towards an explanatory perspective.

These model results can fill existing gaps of knowledge and provide the required information to (1) explore common patterns and differences among small pelagic fish that can highlight the advantages of DVM, (2) improve species identification in acoustic surveys by understanding diel changes in school typology and (3) provide input to individual based models (IBM), such as models of fish growth, that need to incorporate fish movement and behaviour (Pecquerie et al. 2009, Politikos et al. 2011). 


\section{MATERIALS AND METHODS}

\section{Data collection and processing}

Acoustic data

Acoustic data were collected aboard the RV 'Philia' during 3 research surveys in the North Aegean Sea carried out during June 2004, 2005 and 2006 (Fig. 1). Data were recorded using a towed Biosonics Split Beam DT-X echosounder operating at $38 \mathrm{kHz}$. The towed body was set at $2 \mathrm{~m}$ below surface and the vessel speed did not exceed 8 knots. Acoustic sampling took place along predefined parallel transects, which were roughly perpendicular to the bathymetry and with a 10 nautical mile (n mile) distance from each other. Transect design was random (zigzagged) only in semi-closed gulfs (Fig. 1).

Simultaneous to the acoustic sampling, fish samples were collected using a pelagic trawl at sites with high school density to identify species composition and their relative abundance (Simmonds \& MacLennan 2005). During sample hauling, vessel speed approximated 4 knots and echosounding was also carried out.

Acoustic data were analysed using Myriax Echoview software, setting $-70 \mathrm{~dB}$ as the minimum threshold. Echoes recorded less than $0.5 \mathrm{~m}$ above the seabed were excluded from the analysis, and this depth was considered as reference level for the bathymetric measurements. In addition, echoes recorded within $5 \mathrm{~m}$ of the sea surface were also excluded from the analysis. Schools were detected using the software's school detection algorithm, setting $5 \mathrm{~m}$ as minimum length and $1 \mathrm{~m}$ as minimum height for candidate schools. The maximum vertical and horizontal linking distances were set to $2.5 \mathrm{~m}$ and $10 \mathrm{~m}$, respectively. Anchovy schools were assigned during echogram scrutinization taking into account (1) species composition and relative abundance in each area as revealed by the experimental hauls and (2) morphological and energetic characteristics of each school based on previous experience (e.g. Giannoulaki et al. 2005, 2008). In order to minimise errors due to false assignment of schools to species for the study of anchovy DVM, we analysed schools that were recorded exclusively in regions with high relative abundance of anchovy ( $75 \%$ or higher in haul catches by weight; Fig. 1). Anchovy comprised over $75 \%$ of the catch in 42 hauls. We consider this criteria adequate because (1) in the North Aegean Sea anchovy and sardine Sardina pilchardus comprise the vast majority of small pelagic species, (2) the 2 species present discrete characteristics and can be distinguished from each other (e.g. Bay of Biscay:

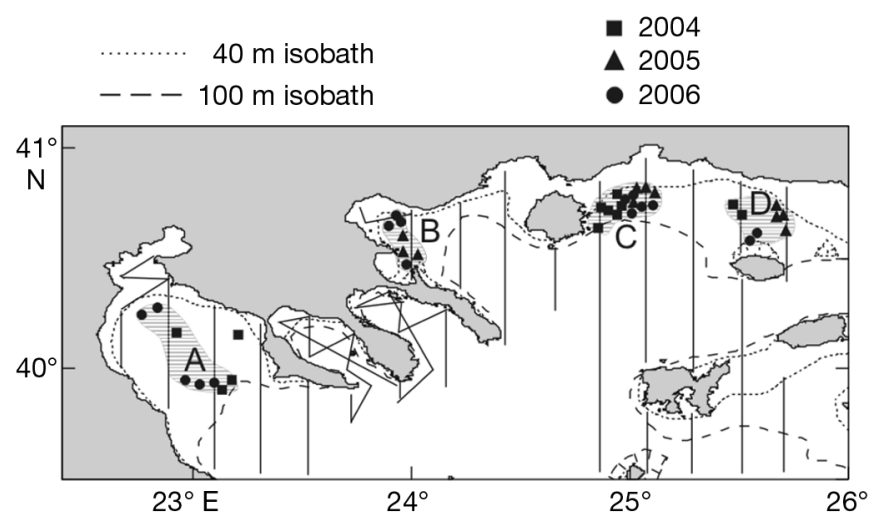

Fig. 1. Study area. Transects of the whole acoustic sampling and $40 \mathrm{~m}$ and $100 \mathrm{~m}$ isobaths are shown. Shaded regions indicate areas with high relative abundance of anchovy ( $>75 \%$ of catches among small pelagic fish). Data included in the analysis derived from research hauls, as well as from parts of the acoustic transects corresponding to the shaded regions (A: 2004, 2006, B: 2005, 2006, C: 2004 to 2006, D: 2004 to 2006). The position of each haul and the respective sampling year is also indicated

Scalabrin et al. 1996; Aegean Sea: Haralabous \& Georgakarakos 1996; A. Machias unpubl. data) and (3) anchovy schools are smaller and their backscatter energy is lower compared to sardine. The latter also means that in areas with $75 \%$ of anchovy in terms of biomass, the number of anchovy schools should exceed $75 \%$. The main small pelagic fish in the area, apart from anchovy and sardine, are round sardinella Sardinella aurita, mackerels (Scomber scombrus and S. japonicus) and horse mackerels (Trachurus trachurus and T. mediterraneus). However, the schools of these species also present discrete characteristics compared to anchovy, for behavioural and anatomical reasons. Nevertheless, the possibility of a few false assignments of schools cannot be excluded.

\section{Environmental data}

Vertical profiles of environmental data were collected with a CTD unit (Seabird SBE25) over a predetermined grid of stations with $10 \mathrm{n}$ mile distances between stations. The CTD was equipped with a Seapoint Fluorometer for chlorophyll a ( $\mathrm{chl} \mathrm{a}$ ) measurements $\left(\mathrm{\mu g} \mathrm{m}^{-3}\right)$ and a scalar irradiance sensor (Biospherical QSP-200PD) to measure light intensity $\left(\mu \mathrm{E} \mathrm{m}{ }^{-2} \mathrm{~s}^{-1}\right.$ where $\left.1 \mu \mathrm{E} \mathrm{m}^{-2} \mathrm{~s}^{-1}=51.2 \mathrm{mc}\right)$ at photosynthetically active radiation wavelengths (light in the range of 400 to $700 \mathrm{~nm}$ ). Geographical coordinates (latitude and longitude), bottom depth and time of day were recorded for each CTD haul. 
During echosounding, time of day, geographic coordinates and bottom depth (i.e. the height of the water column) were automatically recorded for each echo pulse. The mean values of these parameters were extracted for each school following the processing of the echograms. In addition, a series of environmental parameters were estimated at the position of each school in order to investigate whether they are related to DVM. These parameters included (1) the extent of the thermocline, (2) the depth of maximum chl a concentration and (3) light intensity.

The depth of the thermocline has been reported to affect the vertical distribution of pelagic fish (Busch \& Mehner 2009). Waters in the North Aegean Sea are strongly stratified during June (Somarakis et al. 2002). Therefore, we calculated the depth of the upper mixed layer (UML; i.e. depth of the base of the thermocline) as described in Giannoulaki et al. (2005). The depth of the chl a maximum (CM) can be considered as an indicator of the depth layer where high concentrations of mesozooplankton (prey of anchovy) occur (Alcaraz et al. 2007). Finally, light intensity (LI) has been suggested to be one of the main factors controlling DVM behaviour (Blaxter \& Hunter 1982, Fréon \& Misund 1999, Giannoulaki et al. 1999, Nilsson et al. 2003). For this purpose we estimated (1) LI at school depth (school LI) and (2) LI at $5 \mathrm{~m}$ depth (surface LI) because $5 \mathrm{~m}$ was the starting depth for analysing the echoes.

\section{Anchovy school analysis}

\section{Environmental parameter estimation at school location}

Estimation of all parameters (i.e. UML depth, CM depth, surface LI and school LI) was based on modelled data using variables recorded by CTD and took into account the position of each recorded school as well as the time of day. Specifically, latitude, longitude, bottom depth and time of day were used as explanatory variables to model the diurnal changes and spatial distribution of LI and the spatial distribution of CM and UML depths. Generalized additive models (GAMs; Hastie \& Tibshirani 1990) and local regression models (Cleveland 1979) were the statistical techniques used for this purpose.

Concerning UML depth we used the local regression model (LOESS; Cleveland 1979) in a predictive mode to interpolate the values of UML depth as a function of latitude and longitude at anchovy school locations. In LOESS, the model is fitted as a single smooth function of all predictors. The number of nearest neighbours (i.e. size of the neighbourhood), usually expressed as percentage or span of the data points, is a smoothing parameter. A small neighbourhood of $10 \%$ of the data ( $\operatorname{span}=$ 0.1) was used in this study. The S-Plus statistical software (MathSoft) was used for the application of LOESS.

GAMs were used for the modelling of CM depth and LI. A generalized additive model (Hastie \& Tibshirani 1990) is an extension of a generalized linear model in which the linear predictor is given by a specified sum of smooth functions of the covariates (Wood 2006). The 'mgcv' library in the R statistical software (version 2.8.0; R Development Core Team 2008) was used for the application of GAMs. The quasi-Poisson distribution with log link function was used. Independent parameters were transformed, if necessary, to achieve uniform distributions. The natural cubic spline smoother was used for the independent variables to smooth and fit each GAM. Each fit was analysed regarding the generalized cross validation criterion (GCV, the lower the better) and the confidence region for the smoothed function (which should not include zero throughout the range of the predictor). Only significant terms were considered for each model. Validation graphs (e.g. residuals plotted versus fitted values, QQ-plots and residuals plotted against the original explanatory variables) were plotted in order to detect any model misspecification.

For the CM depth modelling we considered (1) latitude, (2) longitude, (3) bottom depth (cubic-root transformed) and (4) year as explanatory variables. Concerning the temporal and spatial (3D) distribution of LI, we considered time and depth as explanatory variables in addition to the aforementioned parameters. Light intensity varies largely according to time of day and water depth because of the absorption of light within the water column. In order to capture the small scale variation in the temporal and spatial distribution of LI and improve model results, different models were applied for (1) period of day (i.e. daytime, dawn-dusk transitional periods) and (2) depth strata (i.e. $<30 \mathrm{~m}, 30-60 \mathrm{~m}, 60-130 \mathrm{~m}$ water column depth). In this way we created data sets with less variance concerning the response variable, and 6 different models ( 2 time periods $\times 3$ depth strata) were finally estimated.

In a subsequent step, the selected models were used in a predictive mode to obtain mean estimates of CM depth and school LI as functions of the independent variables selected. 


\section{Diel school formation}

We followed the approach of Fernandes et al. (2001) to assess school formation. The latter was studied at the elementary distance sampling unit (EDSU) level considered equal to $1 \mathrm{n}$ mile. The approach assumes that as fish start to aggregate into schools early in the morning, the number of schools increases to a constant value during the day and decreases again close to dusk. This pattern is described by a conceptual model (Eq. 1) using the parameters that are illustrated in Fig. 2.

$n=\left\{\begin{array}{cccc}0, & 0 & <t \leq & s_{1} \\ C \cdot \sin ^{2}\left[\frac{\pi\left(t-s_{1}\right)}{e_{1}-s_{1}}\right], & s_{1} & <t \leq s_{1}+\left[\frac{\left(e_{1}-s_{1}\right)}{2}\right] \\ C, & s_{1}+\left[\frac{\left(e_{1}-s_{1}\right)}{2}\right] & <t \leq s_{2}+\left[\frac{\left(e_{2}-s_{2}\right)}{2}\right] \\ C \cdot \sin ^{2}\left[\frac{\pi\left(t-s_{2}\right)}{e_{2}-s_{2}}\right], & s_{2}+\left[\frac{\left(e_{2}-s_{2}\right)}{2}\right] & <t \leq & e_{2} \\ 0, & e_{2} & <t \leq & 23.99\end{array}\right.$

where $t$ is time of day, $C$ is the average number of schools $\mathrm{n}$ mile $^{-1}, s_{1}$ is the time at which schools start to form, $s_{1}+\left(e_{1}-s_{1}\right) / 2$ is the time at which school formation is completed, $s_{2}+\left(e_{2}-s_{2}\right) / 2$ is the time that schools begin to disperse and $e_{2}$ is the time that dispersion has been completed. For the estimation of $s_{1}, e_{1}$, and $s_{2}, e_{2}$, a sine model of the form:

$$
C \cdot \sin ^{2}\left[\frac{\pi(t-s)}{e-s}\right]
$$

was fitted to hourly average values of schools per $\mathrm{n}$ mile, weighted by the total number of schools of all surveys grouped by hour. The sine model was also weighted by the number of observations (equal to the number of $n$ miles) for each hour. Thus, $e_{1}$ is the theoretical time that the morning sine model reaches zero after its peak and $s_{2}$ is the time that the evening sine model starts from zero before its peak (Fig. 2). All time values that we used referred to local time converted to decimal values.

Diurnal patterns in positional, morphometric and energetic school descriptors

Changes in positional, morphometric and energetic descriptors were studied at the school level and thus, each descriptor was extracted or estimated for each anchovy school (Fig. 3). Positional parameters were used to analyse the patterns of bathymetric changes in anchovy schools during the time period that they were present (i.e. from 05:40 until 22:00 h). Energetic and morphometric parameters were used to analyse

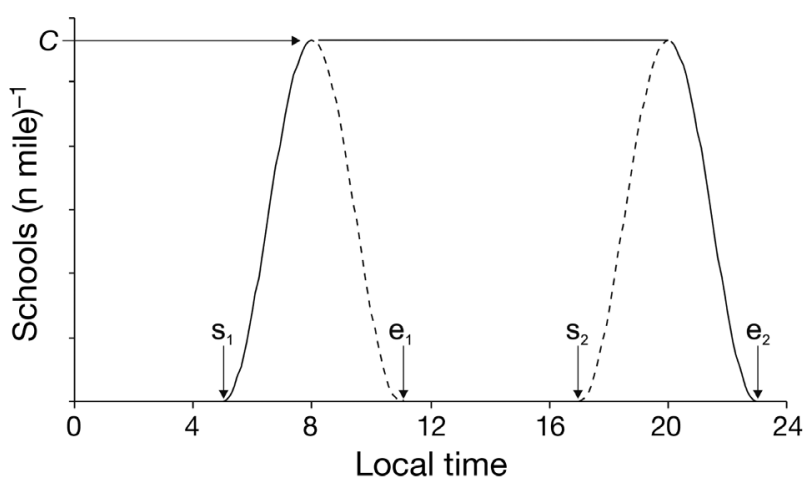

Fig. 2. Engraulis encrasicolus. Conceptual model used to describe the number of anchovy schools per nautical mile (n mile) during different times of the day, according to the parameters explained in Eq. (1). Dotted lines indicated the sine models during the time period that the number of schools is considered constant, according to the conceptual model. $C$ : average number of schools $n$ mile $^{-1}, s_{1}$ : time that schools start to form; $e_{1}$ : theoretical time that the morning sine model reaches zero after its peak; $s_{2}$ : is the time that the evening sine model starts from zero before its peak; $e_{2}$ : time that dispersion has been completed

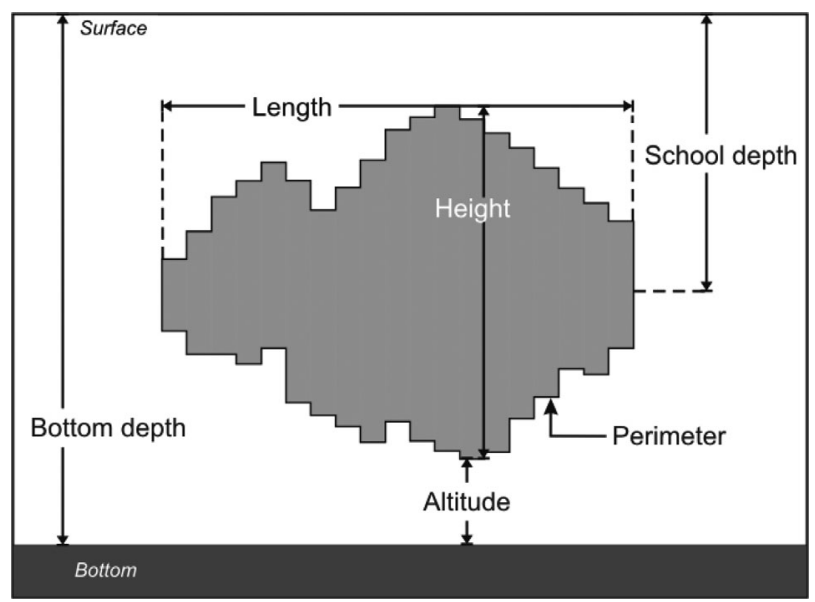

Fig. 3. Engraulis encrasicolus. Example anchovy school as seen in an echogram. Positional and morphometric descriptors used in this analysis are illustrated

changes in internal school structure. Specifically, the following descriptors were used as dependent variables in the analysis of anchovy DVM (Fig. 3). All depth measurements were referenced to the actual sea surface, and school depth values were considered negative (setting surface as the zero point) in order to optimize graphical presentations: (1) Altitude, the distance between the lower extent of the school and the bottom; (2) School depth, the mean depth of the school, as exported by the Echoview software and referenced to school's geometric center; (3) Distance from UML depth, the distance of each 
school from the estimated lower limit of the thermocline at the school position; (4) Distance from CM depth, the distance of each school from the depth where the maximum concentration of chl $a$ was estimated; (5) MVBS, the mean volume back-scattering strength (dB relative to $\mathrm{m}^{2} \times \mathrm{m}^{-3}$ ) considered as a measure of school density; (6) School perimeter, the 2D perimeter of the school, corrected according to Diner's (2001) algorithm, considered as a measure of school size; and (7) Elongation, the ratio of length to height, both corrected according to Diner's (2001) algorithm, and considered a measure of school shape.

In total, data concerning 429 schools pooled from the 3 surveys were used to analyse the diurnal patterns in the vertical distribution of anchovy. For the analysis of the energetic and morphometric changes we excluded the schools that could not be corrected according to the Diner's (2001) algorithm because the correction accuracy decreases when size is small in relation to the beam width (Diner 2001), so the data set for energetic and morphometric changes was restricted to 319 schools.

The diurnal patterns of changes of school descriptors were studied using:

(1) a quadratic model of the form

$$
y=a+b \cdot t+c \cdot t^{2}
$$

where $y$ is the custom school descriptor, $t$ is time and $a, b, c$ are constants,

(2) a cosine model of the form (as described in Giannoulaki et al. 1999)

$$
y=a+b \cdot \cos \left(\frac{2 \pi}{24} t+c\right)
$$

where $y$ is the custom school descriptor, $t$ is the time and $a, b, c$ are constants. The custom descriptor reaches its maximum (or minimum) value at $t_{0}$, the time where the first derivative of the equation equals 0 , and

(3) a GAM described by the equation

$$
g(y)=c+s(t)
$$

where $g$ is the link function, $y$ is the custom school descriptor, $C$ is the intercept, $S$ is a smooth term and $t$ is time. A Gamma distribution with a log link function was selected as the best for our data, except for descriptors that included negative values (i.e. school depth, distance from UML, distance from CM and MVBS) for which a Gaussian distribution was assumed. The natural cubic spline smoother (Hastie \& Tibshirani 1990) was used for the independent variables smoothing and fitting GAMs. In order to avoid any tendency for over-fitting, we increased the amount that the effective degree of freedom of each model counts in the GCV score by a factor $\gamma=1.4$, which has been suggested to largely correct this problem without compromising model fit (Kim \& Gu 2004, Katsanevakis et al. 2009).

Identification of the best model fit was based on the minimization of the Akaike's information criterion (AIC; Burnham \& Anderson 2002). Specifically, the model with the lowest $\mathrm{AIC}$ value $\left(\mathrm{AIC}_{\min }\right)$ better explained the variability of the data, while models with a difference in $\mathrm{AIC}(\triangle \mathrm{AIC})<2\left(\Delta \mathrm{AIC}=\mathrm{AIC}_{\mathrm{i}}-\mathrm{AIC}_{\min }\right)$ also had substantial support from the data and should also be considered (Burnham \& Anderson 2002).

GAMs, as described above, were applied to study the effect of environmental parameters on the variability of anchovy school descriptors during daytime. We used 5 environmental parameters as explanatory variables in GAMs for positional (altitude and school depth) school descriptors: (1) bottom depth at the school's position, (2) school LI, estimated light intensity at a school's specific coordinates, depth and time; (3) surface LI, estimated light intensity at $5 \mathrm{~m}$ depth at a school's specific coordinates and time; (4) CM depth, estimated depth at which chl a concentration was maximum at a school's specific coordinates; and (5) UML depth, estimated depth of the lower limit of the thermocline at a school's specific coordinates. We additionally explored the effect of positional variables, i.e. (1) school depth, (2) altitude, (3) distance from the UML depth, and (4) distance from the CM depth, on school energetic and morphometric descriptors.

Values of the explanatory variables were transformed to achieve uniform distributions when required based on inspection of $\mathrm{QQ}$ plots. A stepwise forward selection was applied to select the best model based on the minimization of AIC (Burnham \& Anderson 2002), as described above.

\section{RESULTS}

\section{Diurnal anchovy school formation}

During the survey period, the sun rose on average just before 06:00 $\mathrm{h}$ local time and set just before 21:00 h. Sun transit was around 13:30 h. Civil twilight was present for approximately half an hour before sunrise and after sunset. Based on the conceptual model fitted to the observed number of anchovy schools per EDSU during the $24 \mathrm{~h}$ period, anchovy schools started to form before 05:00 h local time, just before the start of the civil twilight, reaching a constant number of 1.29 schools $n$ mile $^{-1}$ at $08: 20 \mathrm{~h}$ (Fig. 4). The number of schools started to decrease again before 19:00 $\mathrm{h}$ and reached zero long after the 
end of the civil twilight (Fig. 4). Practically, we have observed schools between 05:40 and 22:00 h local time, while unexpected increases in the number of schools were noted at 08:00 to 09:00 $\mathrm{h}$ and 18:00 to 19:00 h (Fig. 4). During the night (after 22:00 h), layers of fish, or in some cases scattered echo traces not matching the minimum criteria for school detection, were observed close to the surface.

\section{Environmental parameters at school position}

Three LOESS regressions $\left(\mathrm{R}^{2}=0.78\right.$ to 0.90$)$, one for each year, were used to describe the spatial distribution of UML depth, using the geographic coordi-

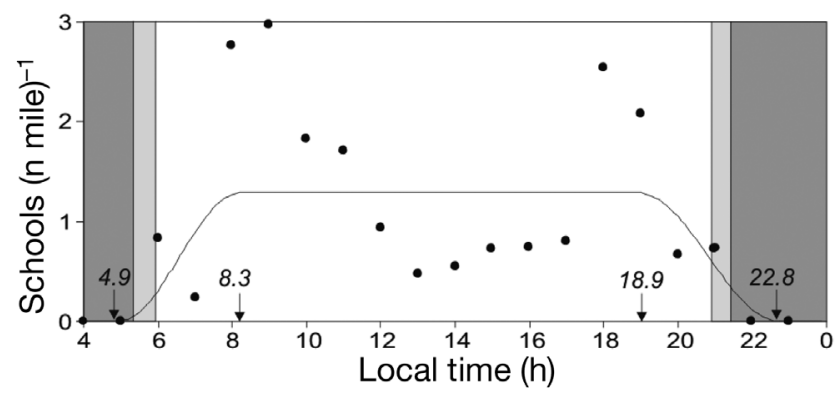

Fig. 4. Engraulis encrasicolus. Fit of conceptual model (Eq. 1, Fig. 2) to (•) hourly average number of anchovy schools $\mathrm{n}$ mile ${ }^{-1}$. Times not shown here (01:00 to 03:00 h) had zero schools detected. Dark grey zones indicate night time; light grey zones indicate periods between the start and end of civil twilight and dawn and dusk, respectively. White zone indicates daytime. Time values are in decimal local time nates as explanatory variables, and estimate its value at each school's geographic position.

GAM analysis for CM depth indicated bottom depth and latitude as significant explanatory variables, explaining $84.4 \%$ of the total deviance. Concerning LI, latitude, longitude, depth, time and year (as factors) were the explanatory variables in all 6 models, explaining 67.3 to $79.7 \%$ of the total deviance. Plots of residuals and response against fitted values did not show any particular trend in any case. For the estimation of LI at school position we used the model corresponding to the depth stratum and the time zone in which each school was observed. Similarly, for the estimation of surface LI (at $5 \mathrm{~m}$ depth), we used the model corresponding to the shallow depth zone and the time zone in which each school was observed.

\section{Diurnal patterns in positional, morphometric and energetic school parameters}

GAMs presented lower AIC values compared to quadratic and cosine models and thus were indicated as the best models to explain the observed changes in positional, energetic and morphometric school descriptors throughout the day (Table 1). In the case of MVBS, both the GAM and cosine models had substantial support from the data (Table 1). Most descriptors peaked around midday according to the cosine model (Table 1). As an example, schools reached their maximum depth around 20 min after sun transit at noon.

Table 1. Engraulis encrasicolus. Comparisons of models applied for the description of the diurnal patterns of anchovy school descriptors (i.e. school descriptor in relation to time) based on Akaike's information criterion (AIC). AICs corresponding to the difference between the model AIC and the lowest AIC value for each descriptor $\left(\triangle \mathrm{AIC}=\mathrm{AIC}_{1}-\mathrm{AIC}_{\min }\right)<2$ are in bold. $a, b, c$ : estimated coefficients for the quadratic and the cosine models; UML: lower limit of the thermocline; CM: depth of maximum chl a concentration; GAM: generalized additive model; MVBS: mean volume back-scattering strength; $t_{0}$ : time of maximum (or minimum) value according to the cosine model

\begin{tabular}{|c|c|c|c|c|c|c|c|c|c|c|}
\hline \multirow[t]{2}{*}{ Descriptor } & \multicolumn{4}{|c|}{ Quadratic model } & \multicolumn{5}{|c|}{ Cosine model } & \multirow{2}{*}{$\begin{array}{l}\text { GAM } \\
\text { AIC }\end{array}$} \\
\hline & AIC & $a$ & $b$ & C & AIC & $a$ & $b$ & C & $t_{0}$ & \\
\hline \multicolumn{11}{|l|}{ Positional } \\
\hline Altitude & 3230.29 & 102.72 & -15.17 & 0.54 & 3289.52 & 17.11 & -20.93 & -9.98 & 12.67 & 1732.31 \\
\hline Depth & 3419.56 & 88.17 & -22.07 & 0.78 & 3399.24 & -37.49 & 32.62 & -25.74 & 13.72 & 3355.82 \\
\hline $\begin{array}{l}\text { Distance from } \\
\text { UML depth }\end{array}$ & 3137.58 & 93.16 & -17.61 & 0.62 & 3117.46 & -8.09 & 25.57 & -13.18 & 12.88 & 3106.51 \\
\hline $\begin{array}{l}\text { Distance from } \\
\text { CM depth }\end{array}$ & 2958.86 & 96.42 & -15.71 & 0.57 & 3036.19 & 9.33 & 22.8 & -0.55 & 12.04 & 2842.33 \\
\hline \multicolumn{11}{|l|}{ Energetic } \\
\hline MVBS & 1795.17 & -61.18 & 1.16 & -0.05 & 1791.44 & -56.2 & 2.45 & 3.1 & 11.79 & 1792.04 \\
\hline \multicolumn{11}{|l|}{ Morphometric } \\
\hline Perimeter & 3459.18 & 158.35 & -11.59 & 0.29 & 3461.09 & 59.28 & -20.13 & -4.96 & 12.33 & 3111.48 \\
\hline Elongation & 2289.06 & -13.98 & 3.39 & -0.12 & 2289.4 & 5.99 & -4.78 & 5.57 & 11.63 & 1939.34 \\
\hline
\end{tabular}


GAMs examining the diurnal variability of school bathymetric descriptors indicated that anchovy schools were mostly located close to the bottom between 9:00 and 20:00 h. A rapid decrease and increase in the altitude was observed before and after these hours respectively (Fig. 5a), whereas maximum school depth was generally observed between 12:00 and 15:00 h (Fig. 5b). Most schools were located close to the thermocline early in the morning (06:00 h) moving well below its lower limit during daytime and rising up again late in the evening (21:00 h; Fig. 5c). Moreover, during the day schools were usually found below the depth of the chl a maximum concentration (Fig. 5d).

Energetic and morphometric school descriptors showed higher diurnal variability (deviance explained $=10.9$ to $14 \%$; not shown here) than bathymetric descriptors (deviance explained $=50.8$ to $77.4 \%$ ). School perimeter was longer during the morning, fluctuated during daytime and showed a tendency to increase at dusk, but a clear pattern was not that apparent (Fig. 6a). In contrast, clear patterns in elongation and MVBS were observed, with schools being more elongated and reflecting more energy per vol- ume unit (i.e. they were more dense) during the daytime (Fig. 6b,c).

The environmental parameters that affected the patterns of anchovy DVM as revealed by GAMs are shown in Table 2. Surface LI and bottom depth explained high percentages of the deviance regarding the positional descriptors. In the case of energetic and morphometric descriptors, altitude was the parameter that mostly explained the observed variability (Table 2). Partial plots of the effect of these variables on school descriptors are shown in Figs. 7 \& 8. Each graph shows the effect of the explanatory variable on the school descriptor, given that the other selected variables remain constant and are included in the model. High values of surface LI urged schools closer to the bottom (on average exhibiting lower values of altitude, Fig. 7a) and to deeper waters. School depth values used are negative, therefore LI effect is reversed and negative effect on school depth practically indicates deeper school positions (Fig. 7c). Moreover, plots indicate that at sites with deeper bottoms, schools tended on average to position deeper in the water column (Fig. 7d) but also at higher distance from the bottom (i.e. higher altitude, Fig. 7b). Bottom
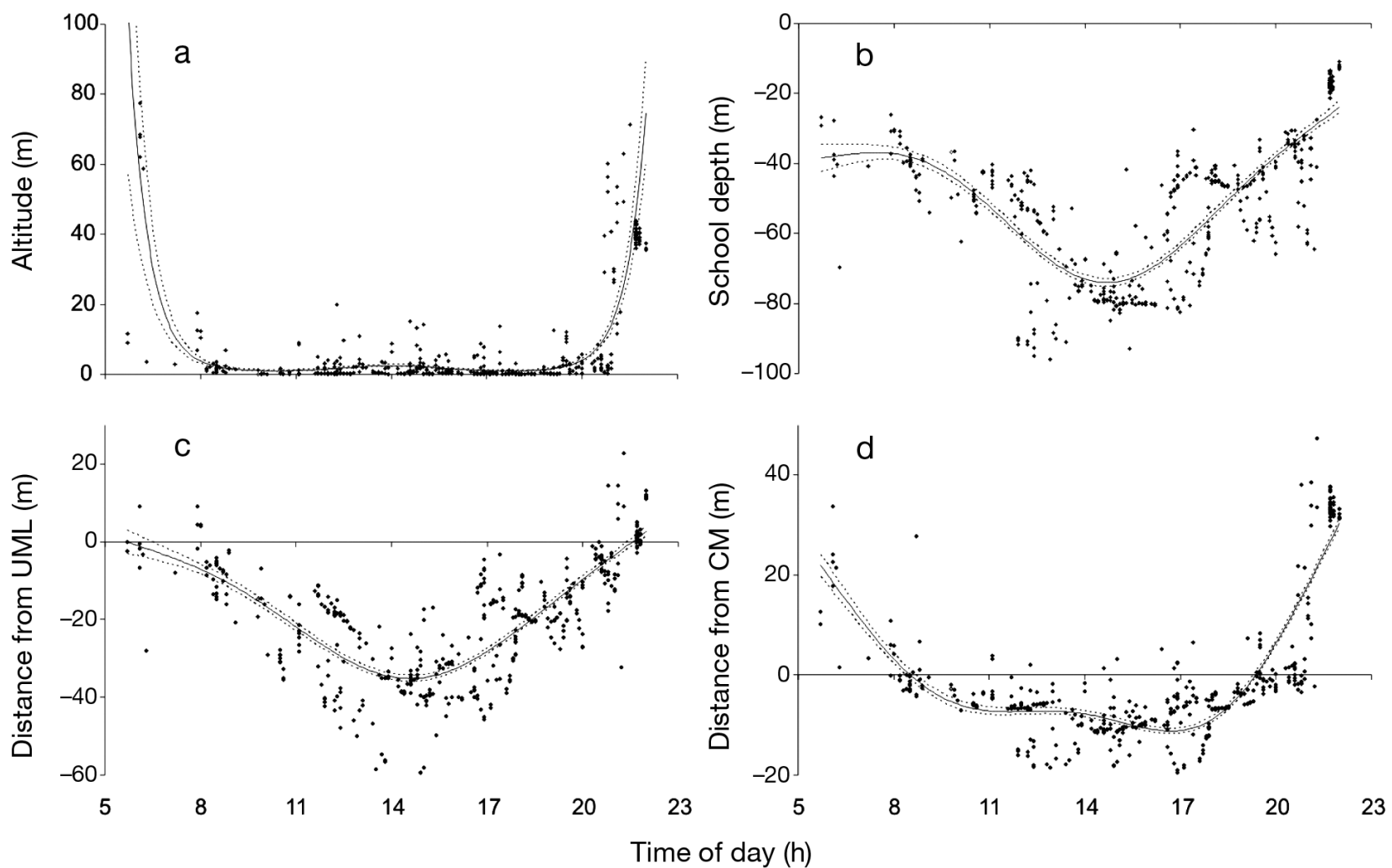

Fig. 5. Engraulis encrasicolus. Fit of generalized additive models (GAMs) of bathymetric school descriptors as (—) a function of time and (........) corresponding standard errors. UML: the depth of the lower limit of the thermocline; CM: depth of maximum concentration of chla 

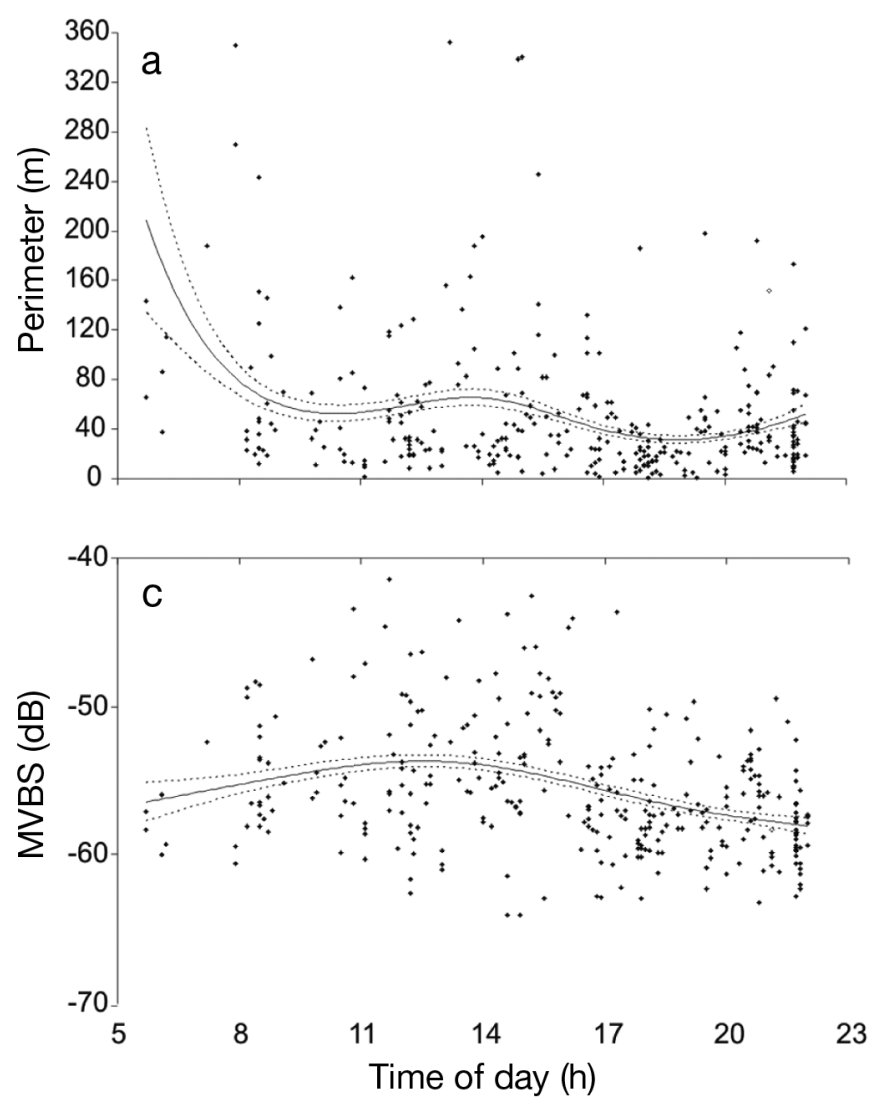

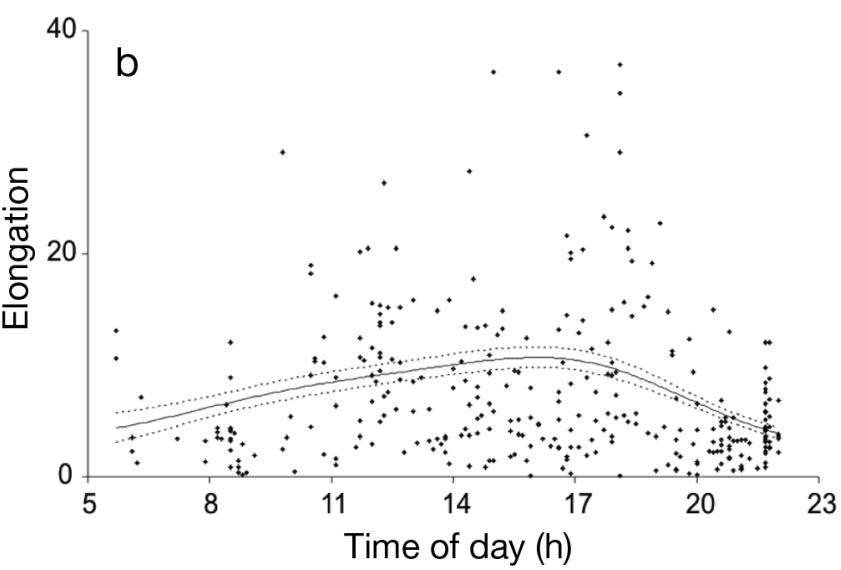

Fig. 6. Engraulis encrasicolus. Fit of generalized additive models (GAMs) for ( $a, b) 2$ morphometric (perimeter, elongation) and (c) energetic (mean volume back-scatter; MVBS) school descriptors as a function of (-) time and (........) corresponding standard errors

Table 2. Engraulis encrasicolus. Analysis of deviance for generalized additive models (GAMs) of anchovy school descriptors in relation to environmental parameters. Forward selection and final models are shown. AIC: Akaike's information criterion; s: smooth function; Bottom: cubic root transformation of bottom depth; Surface LI: logarithmic transformation of light intensity in the surface; School LI: logarithmic transformation of light intensity at school position

\begin{tabular}{|c|c|c|c|c|c|c|}
\hline Descriptor & Model & $\begin{array}{c}\text { Residual } \\
\text { df }\end{array}$ & $\begin{array}{l}\text { Residual } \\
\text { deviance }\end{array}$ & $\begin{array}{c}\text { Deviance } \\
\text { explained (\%) }\end{array}$ & AIC & $\mathrm{p}$ \\
\hline \multicolumn{7}{|l|}{ Bathymetric } \\
\hline \multirow[t]{3}{*}{ Altitude } & Null & 428.00 & 1646.02 & & 2129.90 & \\
\hline & s(Surface LI) & 424.89 & 966.63 & 41.3 & 1827.46 & $<0.001$ \\
\hline & $\mathrm{s}($ Surface LI) + s(Bottom) & 422.36 & 806.86 & 51.0 & 1733.59 & $<0.001$ \\
\hline \multirow[t]{3}{*}{ Depth } & Null & 428.00 & 169767.90 & & 3787.18 & \\
\hline & s(Surface LI) & 424.16 & 67451.70 & 60.3 & 3398.89 & $<0.001$ \\
\hline & $\mathrm{s}($ Surface LI) $+\mathrm{s}($ Bottom $)$ & 420.30 & 15801.08 & 90.7 & 2783.98 & $<0.001$ \\
\hline \multicolumn{7}{|l|}{ Energetic } \\
\hline \multirow[t]{4}{*}{ MVBS } & Null & 318.00 & 5790.07 & & 1833.97 & \\
\hline & s(Altitude) & 316.81 & 5177.61 & 10.6 & 1800.68 & $<0.001$ \\
\hline & $\mathrm{s}($ Altitude $)+\mathrm{s}($ Bottom $)$ & 314.52 & 4652.60 & 19.6 & 1771.15 & $<0.001$ \\
\hline & $\mathrm{s}($ Altitude $)+\mathrm{s}($ Bottom $)+\mathrm{s}($ School LI $)$ & 311.08 & 4334.62 & 25.1 & 1755.45 & $<0.001$ \\
\hline \multicolumn{7}{|c|}{ Morphometric } \\
\hline \multirow[t]{4}{*}{ Perimeter } & Null & 318.00 & 289.13 & & 3145.31 & \\
\hline & s(Altitude) & 315.04 & 232.89 & 19.5 & 3073.36 & $<0.001$ \\
\hline & $\mathrm{s}($ Altitude $)+\mathrm{s}($ Bottom $)$ & 313.54 & 220.57 & 23.7 & 3057.05 & $<0.001$ \\
\hline & $\mathrm{s}($ Altitude $)+\mathrm{s}($ Bottom $)+\mathrm{s}($ School LI $)$ & 311.85 & 202.60 & 29.9 & 3030.44 & $<0.001$ \\
\hline \multirow[t]{2}{*}{ Elongation } & Null & 318.00 & 311.70 & & 1977.45 & \\
\hline & s(Altitude) & 314.45 & 227.28 & 27.1 & 1870.53 & $<0.001$ \\
\hline
\end{tabular}



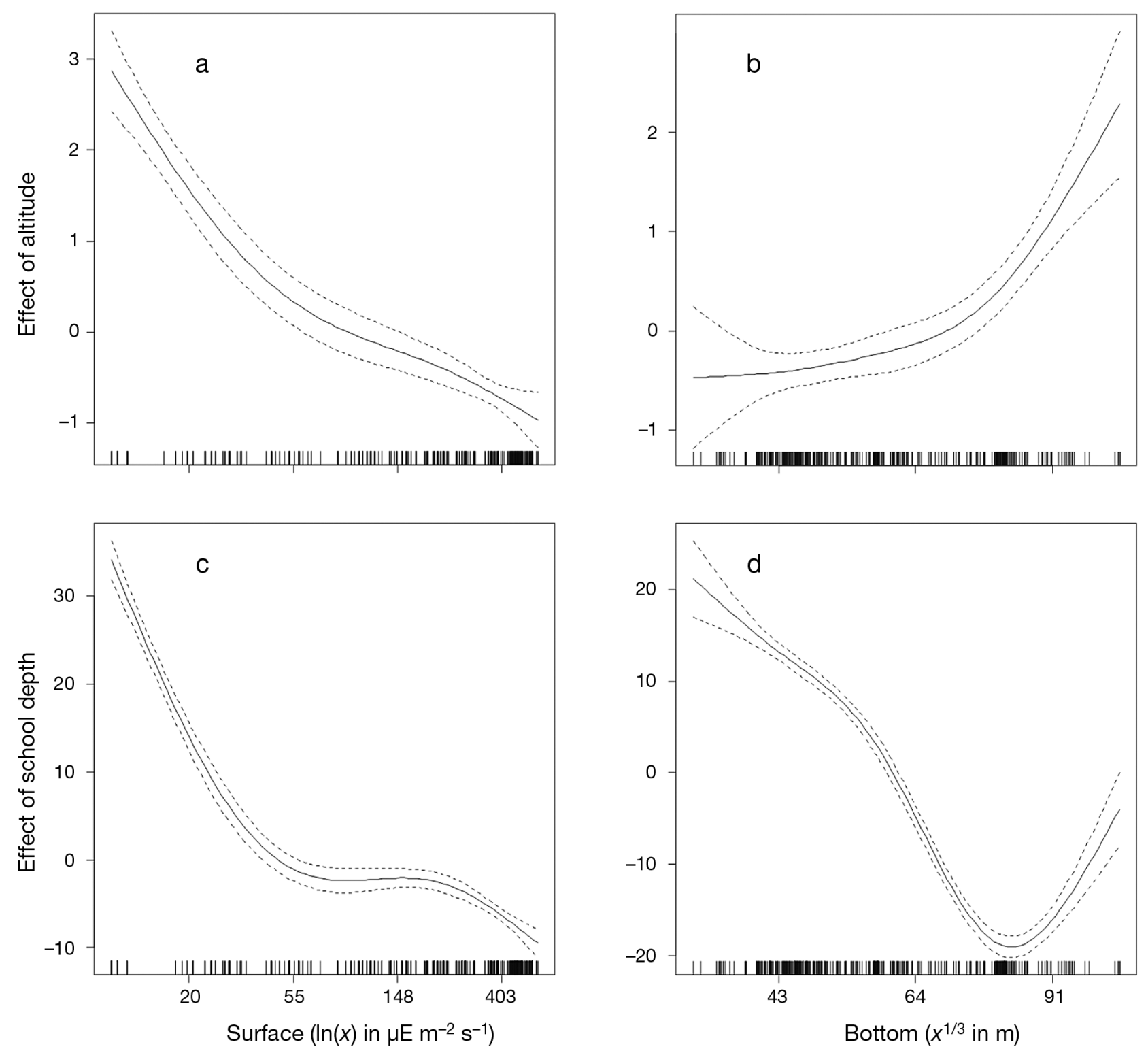

Fig. 7. Engraulis encrasicolus. Estimated smooth terms of the environmental parameters contributing to the generalized additive models (GAMs) for bathymetric school descriptors: $(a, b)$ Altitude and (c,d) School depth. $95 \%$ confidence intervals are shown with dotted lines. Surface LI: log transformed (natural logarithm) values of light intensity in the surface; Bottom: cubic root transformed values of bottom depth. Note that, while original values prior to transformation can be visualized in $x$-axes (rug plots), scales are relative to the specific transformations

depth limited the downward distribution of schools as there was no apparent effect on altitude up to almost $80 \mathrm{~m}$ depth. At greater bottom depth $(>80 \mathrm{~m})$ school depth seems not to be so strongly affected because the effect tended to reverse (Fig. 7b).

High values of MVBS (more dense school structure) were associated with low values of altitude, deeper bottom depths and high values of school LI (Fig. 8a-c). Perimeter was larger at high values of altitude, bottom depth and school LI (Fig. 8d-f).
Finally, elongation was positively affected by lower altitude, indicating more elongated school shapes occurred close to the bottom ( $<1$ m, Fig. 8g).

\section{DISCUSSION}

Diel vertical migration (DVM) is a common behaviour among small pelagic fish, with most species exhibiting downward migration after sunrise and 

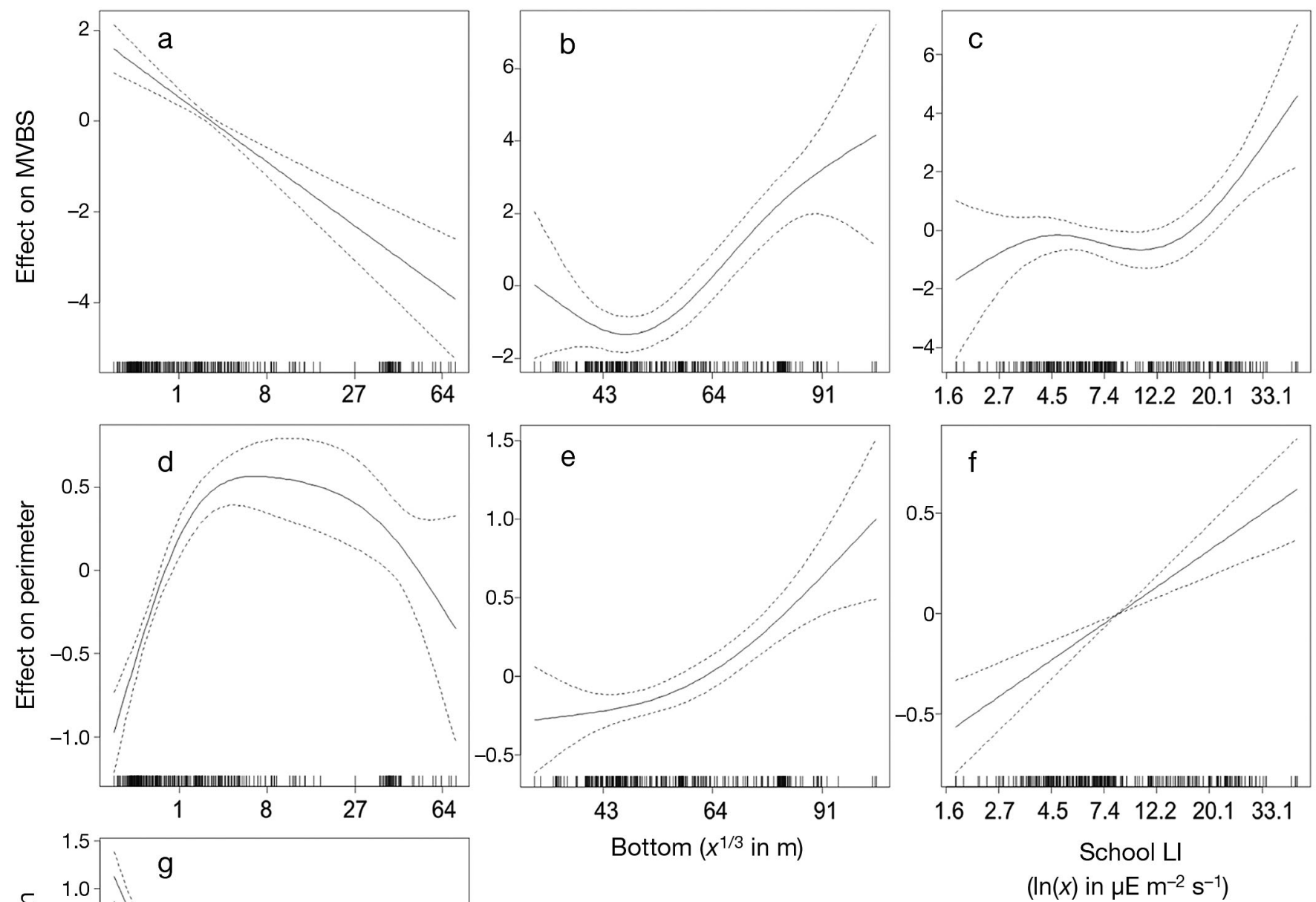

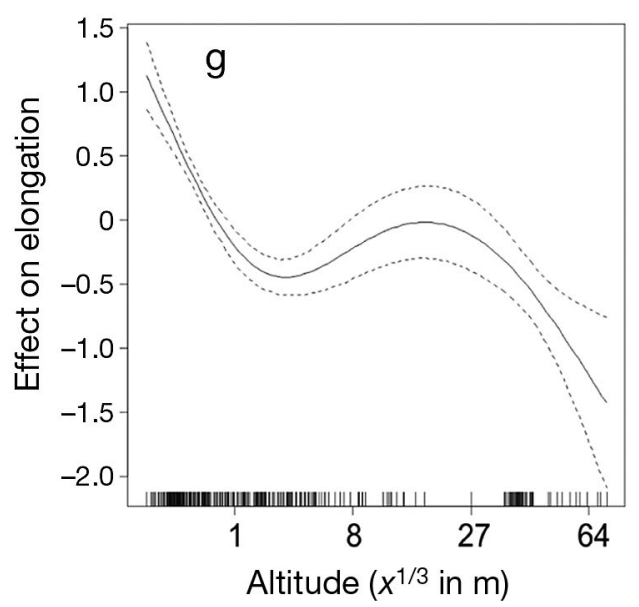

returning into shallow water depths at dusk (Blaxter \& Hunter 1982). Our objective was to explore the changes in anchovy schooling behaviour within the DVM framework in an effort to identify the behavioural and ecological patterns involved. Existing studies on European anchovy DVM are scant, mostly referring to species' vertical distributions (Massé et al. 1996, D'Elia et al. 2009) and/or school morphological variability (Massé et al. 1996, Iglesias et al. 2003, D'Elia et al. 2009). Instead, we have put this informa- tion in the context of a diel cycle and searched for the environmental variables that drive the mechanism underneath.

\section{School formation}

School formation and dispersion may be species specific or may even differ intraspecifically, affected by abiotic (e.g. light intensity; Blaxter \& Hunter 1982) 
and biotic factors (e.g. prey availability; Bertrand et al. 2006). Schooling of European anchovy in the Aegean Sea was observed only during daytime, including the transitional periods, which was in agreement with findings by Iglesias et al. (2003) from the western Mediterranean, while during the night layers of dispersed fish were observed. This is not the case for sardine, the other important small pelagic species in the Mediterranean Sea. For this species contradictory results have been reported, stating that schools either disperse (Giannoulaki et al. 1999, Iglesias et al. 2003) or remain together during the nighttime (Fréon et al. 1996, Zwolinski et al. 2007). In this sense, diurnal formation and dispersion of anchovy schools seems to be consistent and similar to those described for Atlantic herring Clupea harengus, the schools of which disperse during the night (Fernandes et al. 2001, Nilsson et al. 2003). In the present study a conceptual model was used to explore school formation and subsequently provide a rough estimate of the times that anchovy schools are available to detect by echosounder. According to this model, anchovy schools start to form just before dawn, reach a constant number of schools per nautical mile later in the morning $(08: 20 \mathrm{~h})$ and decrease in number again in the evening (before 19:00 h). The observed increase in the number of schools in the morning suggests that fish start to form small aggregations, in terms of numbers of individuals, at dawn, resulting in a high number of schools around 08:00 to 09:00 h. Smaller schools merge to become progressively larger with a subsequent decrease in the number of schools. The opposite behaviour is probably the reason for an analogous rise in the number of schools observed in the evening (18:00 to 19:00 h). Even though schools are observed long before and after the hours that school formation and dispersion have been completed, defining the period of maximum school availability is important when designing acoustic surveys or analysing acoustic data collected both during daytime and night-time (Fernandes et al. 2001). Ignoring DVM can lead to significant biomass underestimations, due to fish migration towards the surface blind zone or changes in the tilt angle of individual fish and the subsequent effect on target strength.

\section{Factors affecting the diurnal school variability}

Besides the number of schools varying within the diurnal cycle, school formation and dispersion are also described here in terms of changes in school position, size, shape and density. Although these parameters present high variability during the diel cycle, clear diurnal patterns are apparent in almost all anchovy school descriptors. The values of most of these descriptors are similar during morning and evening but differ during daytime. Smooth terms (GAMs) were found to perform better when used to explain these patterns particularly when describing the rapid changes that occur during the transitional periods. However, simpler models (quadratic, cosine), which are easier to use in a predictive mode, satisfactorily described these diurnal patterns as well. In addition, the use of such models allows the determination of time that each parameter peaks during the day and the comparison of results across species or populations. For example, the cosine model showed that anchovy schools reach their maximum depth soon after the sun transit. Similar results have been obtained by using a cosine model for sardine in the Aegean Sea (Giannoulaki et al. 1999). The present study has shown that anchovy exhibit behaviour typical of forage fish (Blaxter \& Hunter 1982), migrating downwards at sunrise and returning to shallower levels prior to sunset. During daytime, schools were clearly located at small distances from the bottom, usually in the vicinity of the chl a maximum. In the Mediterranean, high concentrations of mesozooplankton (anchovy prey) are often associated with the deep chl a maximum that forms during the summer (Alcaraz et al. 2007), and anchovy seem to take advantage of this, feeding primarily during the daytime (Tudela \& Palomera 1997). The observed match between school depth and chl a maximum depth is much stronger around dusk (after 20:00 h) when anchovy exhibits their summer daily feeding peak in the Aegean Sea (Nikolioudakis et al. 2009).

The vertical position of anchovy was found to be primarily driven by surface light intensity, similar to the findings of previous studies on small pelagic fish (Fréon \& Misund 1999, Busch \& Mehner 2009). Fish are not expected to respond to absolute levels of surface light intensity, though light changes are shed into the whole water column and trigger fish to migrate deeper (e.g. Giannoulaki et al. 1999) in order to remain in relatively low levels of luminance (Nilsson et al. 2003). However, we have to note that the light range considered here (photosynthetically active radiation, 400 to $700 \mathrm{~nm}$ ) was not in the range of UV that may affect school characteristics directly (e.g. shoaling decisions; Modarressie et al. 2006) or indirectly (e.g. by affecting the vertical distribution of their prey; Rhode et al. 2001). The effect of UV concerning the patterns of DVM in anchovy and other species should be further examined. 
Water stratification has been reported to place an upper constraint on the vertical position of fish in well stratified environments like lakes (Busch \& Mehner 2009). However, in the Aegean Sea, the presence of dense structured thermoclines did not constrain the vertical distribution of anchovy. Most schools were located above the lower limit of the thermocline early in the morning (06:00 h), moving well below it in daytime and rising up again in late evening (21:00 h). Oxygen levels have also proved to be a factor that greatly affects the vertical distribution of pelagic fish (Parker-Stetter \& Horne 2009, Bertrand et al. 2010). Bertrand et al. (2010) showed that the habitat volume of Engraulis rigens in the South Pacific off Peru can be estimated based on the upper limit of the oxygen minimum zone. Although a lack of available data prevented an analysis concerning the effect of oxycline in the present study, oxygen stratification in the Aegean Sea is known to follow the temperature stratification (Lykousis et al. 2002) and thus, the thermocline can be considered to be a proxy for the oxycline. Taking this into account, this parameter seems not to affect the vertical distribution of anchovy, at least not to the extent that was identified in the case of Peruvian anchovy.

In contrast, bottom depth was found to limit the downwards movement of anchovy in shallow depths. During the daytime, anchovy schools were in close association with the bottom in waters less than $80 \mathrm{~m}$ deep. Beyond this depth, distance from the bottom seems to increase. Similar observations of sea bottom constraining downward movement of fish have also been reported for other species, like the blue whiting Micromesistius poutassou (Johnsen \& Godø 2007) and sardine (Giannoulaki et al. 1999). However, the results of the present study contradict those reported for the Bay of Biscay where anchovy schools were generally found at a constant altitude of approximately $16 \mathrm{~m}$ above the bottom or even further when predators like horse mackerel were present near the bottom (Massé et al. 1996). Other abiotic factors, like substrate type (D'Elia et al. 2009) and hydrological variations (Massé et al. 1996), or biotic factors, like the presence of competitors and predators (Massé et al. 1996), may also affect the vertical distribution of fish schools.

Concerning the internal school structure, a clear diurnal pattern in school shape was apparent with elongation being low during the morning and the afternoon and higher during the day. Increased perimeter (a measure of school size) was observed at dawn and coincided with low school density, indicating that schools start to form as loose aggregations and become more compact later during daytime. Substantial reduction in school density was also observed at dusk, following the typical pattern of the diurnal schooling behaviour of small pelagic fish (Fréon et al. 1996, Zwolinski et al. 2007, Bertrand et al. 2008). Larger school formations during the transitional periods have been reported both when fish remain in loose aggregations during the night (e.g. in sardine; Zwolinski et al. 2007) and when they disperse, as in the case of herring (Fernandes et al. 2001). In our case, although school perimeter shows relatively increased values at dusk, the difference compared to midday is small. This could be attributed to a progressive break of the larger schools into smaller ones as time goes by and light decreases. Similarly, Fréon et al. (1996) did not detect a clear diurnal pattern in the school size of pelagic fish in the western Mediterranean but observed that the number of schools increased during darker periods, implying a progressive breaking behaviour of large schools into smaller ones. The general pattern of forming loose aggregations at night, although part of a standard behaviour, might differentiate among species (i.e. anchovy, sardine and herring), size of fish, size and density of schools or regional location (i.e. Mediterranean Sea and Atlantic).

Moreover, our results indicate that bottom depth affects most of the studied school descriptors, which is in agreement with the findings presented by D'Elia et al. (2009) for the Sicilian Channel. Morphometric and energetic features of anchovy schools in the study area are primarily affected by the bathymetric changes in schools, particularly regarding their distance from the bottom (i.e. altitude). Anchovy schools close to the seabed generally presented a more elongated form (discoidal shape). Discoidal shapes of schools close to the bottom have also been described by Misund (1993). The close association with the seabed could be interpreted as a mechanism for predator avoidance. Even though a more spherical shape in the mid-waters can minimize detection from predators, this may not be the case for schools found close to bottom (Misund 1993). Spreading along the seabed (presenting a more elongated shape with reduced relative height) where the background contrast is low might be a mechanism to reduce detectability from predators. In addition, anchovy schools are smaller when found close to the seabed (i.e. smaller perimeter) thus further decreasing detection probability. The reduction in school size is associated with an increase in school density, implying the formation of more compact schools while probably maintaining a 
relatively high number of individuals. Larger schools, in terms of the number of constituent fish, can provide increased survival probability at the individual level during a predator attack (Fréon \& Misund 1999). Thus this schooling feature could also be related to predator avoidance behaviour.

Light intensity at school depth also affects the internal structure of anchovy schools. School density was higher at higher values of light intensity. Because dense structures are assumed to be more effective in predator avoidance (Fréon \& Misund 1999) this feature may also reflect an anti-predatory mechanism. Such a mechanism could be particularly important during the day when light availability facilitates school detection by predators supporting other senses or mechanisms related to noise detection. Moreover, the observed increase of the school perimeter at high levels of light intensity along with increased school density further supports the scenario of small schools merging into larger ones.

The environmental parameters considered here explained less variance concerning the morphometric and energetic school descriptors than the bathymetric ones did. This underlines the high plasticity in school size, shape and density that may be affected by numerous environmental parameters and in a less deterministic way. Shape reflects the dynamics of school internal structure, with individuals moving continuously (Misund 1993, Fréon \& Misund 1999) in response to external stimuli (e.g. Massé et al. 1996, Gerlotto et al. 2006). For example, feeding may alter schooling behaviour, resulting in looser aggregations (Fréon \& Misund 1999). Evidence that moderate changes in the internal school structure of anchovy could be related to feeding is also implied by our findings. A preliminary analysis on the daily feeding pattern of anchovy in the area during summer (July) indicated that stomach fullness presented relatively high values approximately after 16:30 h (local time) that continued until after sunset (Nikolioudakis et al. 2009). Based on our findings, a decrease in school density is observed after a midday peak at 12:40 h. This decreasing trend reaches its maximum rate at approximately the same time that feeding is intensified (16:40 h local time; rate not shown here).

When comparing anchovy school characteristics during daytime among populations from various areas, certain similarities and differences seem to arise. The vast majority of anchovy schools are found in depths less than $80 \mathrm{~m}$ in the Aegean Sea (this study), Central Mediterranean (D' Elia et al. 2009), Western Mediterranean (Iglesias et al. 2003) as well as the Bay of Biscay (Massé et al. 1996, Scalabrin et al. 1996). Schools in the Bay of Biscay (Massé et al. 1996, Scalabrin et al. 1996) and the Central Mediterranean (D' Elia et al. 2009) are usually observed further from the bottom than in the Aegean Sea. Backscattering strength is higher in the Bay of Biscay (Scalabrin et al. 1996) than that in our findings, which may be related to differences in school density, physiological status and/or the size of the individuals. Elongation was found to be similar in all areas (Massé et al. 1996, Scalabrin et al. 1996, D' Elia et al. 2009). Regional comparisons of patterns related to anchovy DVM remain to be examined.

\section{CONCLUSIONS}

Our findings have revealed several behavioural patterns related to the diurnal vertical migration of anchovy in the Aegean Sea. Fish spent most of the daytime in association with the bottom, close but below the depth of maximum chlorophyll concentration and going deeper when surface light intensity increases. Patterns in the morphometric and energetic school descriptors underlie the dynamic aspect of schooling, which is largely explained by a tradeoff between feeding and predator avoidance. Verification of these findings in a broader temporal and regional scale seems important because several aspects of DVM may change seasonally (Busch \& Mehner 2009) or regionally, affected by environmental or population specificities. Better understanding of the diurnal intra-specific variability in school descriptors would contribute to studies for species identification, which remains a key aspect of concern in fisheries acoustics (Korneliussen et al. 2009). For example, species identification could be more accurate when the time of day of the observed schools is taken into account (Lawson et al. 2001) or by defining school types related to time. In addition, acoustic estimates could be more accurate when also considering the hours that assure the maximum availability of the target species to echosounding (Fernandes et al. 2001).

Moreover, this knowledge can improve the understanding of species spatial organization and habitat utilization (Mackinson et al. 1999) as well as highlight similarities and differences among species and populations that can shed light on the evolutionary advantages of the vertical migration and related behaviours. Finally, the description of patterns comprises basic information to support the needs of advanced ecological modelling, like improving the accuracy of individual-based bioenergetic models. 
Acknowledgements. The authors acknowledge the captain and the crew of RV 'Philia' for their invaluable help during the research surveys, S. Katsanevakis for suggestions and advice concerning the data analysis, and the 3 anonymous referees for their valuable comments and suggestions that greatly helped in improving the manuscript.

\section{LITERATURE CITED}

Alcaraz M, Calbet A, Estrada M, Marrasé C, Saiz E, Trepat I (2007) Physical control of zooplankton communities in the Catalan Sea. Prog Oceanogr 74:294-312

Bertrand A, Barbieri MA, Gerlotto F, Leiva F, Córdova J (2006) Determinism and plasticity of fish schooling behaviour as exemplified by the South Pacific jack mackerel Trachurus murphyi. Mar Ecol Prog Ser 311:145-156

> Bertrand A, Gerlotto F, Bertrand S, Gutiérrez M and others (2008) Schooling behaviour and environmental forcing in relation to anchoveta distribution: an analysis across multiple spatial scales. Prog Oceanogr 79:264-277

> Bertrand A, Ballón M, Chaigneau A (2010) Acoustic observation of living organisms reveals the upper limit of the oxygen minimum zone. PLoS ONE 5:e10330

Blaxter JHS, Hunter JR (1982) The biology of the clupeoid fishes. Adv Mar Biol 20:1-223

Burnham KP, Anderson DR (2002) Model selection and multimodel inference: a practical information-theoretic approach, 2nd edn. Springer, New York, NY

Busch S, Mehner T (2009) Hydroacoustic estimates of fish population depths and densities at increasingly longer time scales. Int Rev Hydrobiol 94:91-102

> Castillo J, Robotham H (2004) Spatial structure and geometry of schools of sardine (Sardinops sagax) in relation to abundance, fishing effort, and catch in northern Chile. ICES J Mar Sci 61:1113-1119

Clark CW, Levy DA (1988) Diel vertical migrations by juvenile sockeye salmon and the antipredation window. Am Nat 131:271-290

> Cleveland WS (1979) Robust locally weighted regression and smoothing scatterplots. J Am Stat Assoc 74:829-836

D'Elia M, Patti B, Sulli A, Tranchida G and others (2009) Distribution and spatial structure of pelagic fish schools in relation to the nature of the seabed in the Sicily Straits (Central Mediterranean). PSZN I: Mar Ecol 30(Suppl S1): $151-160$

Diner N (2001) Correction on school geometry and density: approach based on acoustic image simulation. Aquat Living Resour 14:211-222

Fernandes PG, Macdonald L, Aukland R, Reid D, Simmonds EJ, Shanks A (2001) Changes in the availability of herring to the North Sea acoustic survey; the impact of diurnal migration. Catchability and abundance indicators the influence of environment and fish behaviour. ICES CM Q:08. ICES, Copenhagen

Fréon P, Misund OA (1999) Dynamics of pelagic fish distribution and behaviour: effects on fisheries and stock assessment. Blackwell Science, Oxford

Fréon P, Gerlotto F, Soria M (1992) Changes in school structure according to external stimuli: description and influence on acoustic assessment. Fish Res 15:45-66

Fréon P, Soria M, Mullon C, Gerlotto F (1993) Diurnal variation in fish density estimate during acoustic surveys in relation to spatial distribution and avoidance reaction. Aquat Living Resour 6:221-234
Fréon P, Gerlotto F, Soria M (1996) Diel variability of school structure with special reference to transition periods. ICES J Mar Sci 53:459-464

- Gerlotto F (1993) Identification and spatial stratification of tropical fish concentrations using acoustic populations. Aquat Living Resour 6:243-254

> Gerlotto F, Bertrand S, Bez N, Gutierrez M (2006) Waves of agitation inside anchovy schools observed with multibeam sonar: a way to transmit information in response to predation. ICES J Mar Sci 63:1405-1417

Giannoulaki M, Machias A, Tsimenides N (1999) Ambient luminance and vertical migration of the sardine Sardina pilchardus. Mar Ecol Prog Ser 178:29-38

Giannoulaki M, Machias A, Somarakis S, Tsimenides N (2005) The spatial distribution of anchovy and sardine in the northern Aegean Sea in relation to hydrographic regimes. Belg J Zool 135:151-156

Giannoulaki M, Valavanis VD, Palialexis A, Tsagarakis K, Machias A, Somarakis S, Papaconstantinou C (2008) Modelling the presence of anchovy Engraulis encrasicolus in the Aegean Sea during early summer, based on satellite environmental data. Hydrobiologia 612:225-240

> Haralabous J, Georgakarakos S (1996) Artificial neural networks as a tool for species identification of fish schools. ICES J Mar Sci 53:173-180

Hastie T, Tibshirani R (1990) Generalized additive models. Chapman \& Hall, London

> Iglesias M, Carrera P, Muiño R (2003) Spatio-temporal patterns and morphological characterisation of multispecies pelagic fish schools in the North-Western Mediterranean Sea. Aquat Living Resour 16:541-548

Johnsen E, Godø OR (2007) Diel variations in acoustic recordings of blue whiting (Micromesistius poutassou). ICES J Mar Sci 64:1202-1209

> Katsanevakis S, Maravelias CD, Damalas D, Karageorgis AP, Tsitsika EV, Anagnostou C, Papaconstantinou C (2009) Spatiotemporal distribution and habitat use of commercial demersal species in the eastern Mediterranean Sea. Fish Oceanogr 18:439-457

Kim YJ, Gu C (2004) Smoothing spline Gaussian regression: more scalable computation via efficient approximation. J R Stat Soc B 66:337-356

Korneliussen RJ, Heggelund Y, Eliassen IK, Johansen GO (2009) Acoustic species identification of schooling fish. ICES J Mar Sci 66:1111-1118

> Lawson GL, Barange M, Fréon P (2001) Species identification of pelagic fish schools on the South African continental shelf using acoustic descriptors and ancillary information. ICES J Mar Sci 58:275-287

> Levy DA (1990a) Reciprocal diel vertical migration behavior in planktivores and zooplankton in British Columbia lakes. Can J Fish Aquat Sci 47:1755-1764

> Levy DA (1990b) Sensory mechanism and selective advantage for diel vertical migration in juvenile sockeye salmon, Oncorhynchus nerka. Can J Fish Aquat Sci 47: 1796-1802

Lleonard J, Maynou F (2003) Fish stock assessments in the Mediterranean: state of the art. Sci Mar 67(Suppl 1): 37-49

Lykousis V, Chronis G, Tselepides A, Price NB and others (2002) Major outputs of the recent multidisciplinary biogeochemical researches undertaken in the Aegean Sea. J Mar Syst 33-34:313-334

Machias A, Stergiou IK, Somarakis S, Karpouzi VS, Kapantagakis A (2008) Trends in trawl and purse seine catch 
rates in the north-eastern Mediterranean. Mediterr Mar Sci 9:49-65

Mackinson S, Nøttestad L, Guénette S, Pitcher T, Misund OA, Fernö A (1999) Cross-scale observations on distribution and behavioural dynamics of ocean feeding Norwegian spring-spawning herring (Clupea harengus L.). ICES J Mar Sci 56:613-626

Massé J (1996) Acoustic observations in the Bay of Biscay: schooling, vertical distribution, species assemblages and behaviour. Sci Mar 60(Suppl 2):227-234

Massé J, Koutsikopoulos C, Patty W (1996) The structure and spatial distribution of pelagic fish schools in multispecies clusters: an acoustic study. ICES J Mar Sci 53: $155-160$

Misund OA (1993) Dynamics of moving masses: variability in packing density, shape, and size among herring, sprat, and saithe schools. ICES J Mar Sci 50:145-160

- Modarressie R, Rick IP, Bakker TCM (2006) UV matters in shoaling decisions. Proc R Soc B 273:849-854

$>$ Neverman D, Wurtsbaugh WA (1994) The thermoregulatory function of diel vertical migration for a juvenile fish, Cottus extensus. Oecologia 98:247-256

Nikolioudakis N, Giannoulaki M, Machias A, Somarakis S (2009) Daily feeding pattern of european anchovy (Engraulis encrasicolus) during July 2007. Proc 9th Hell Symp Oceanogr Fish. HCMR, Athens, p 810-815 (in Greek)

Nilsson LAF, Thygesen UH, Lundgren B, Nielsen BF, Nielsen JR, Beyer JE (2003) Vertical migration and dispersion of sprat (Sprattus sprattus) and herring (Clupea harengus) schools at dusk in the Baltic Sea. Aquat Living Resour 16:317-324

Paramo J, Bertrand S, Villalobos H, Gerlotto F (2007) A three-dimensional approach to school typology using vertical scanning multibeam sonar. Fish Res 84:171-179

Parker-Stetter SL, Horne JK (2009) Nekton distribution and midwater hypoxia: a seasonal, diel prey refuge? Estuar Coast Shelf Sci 81:13-18

Pecquerie L, Petitgas P, Kooijman SALM (2009) Modeling fish growth and reproduction in the context of the Dynamic Energy Budget theory to predict environmental

Editorial responsibility: Konstantinos Stergiou,

Thessaloniki, Greece impact on anchovy spawning duration. J Sea Res 62: 93-105

Politikos DV, Triantafyllou G, Petihakis G, Tsiaras K, Somarakis S, Ito SI, Megrey BA (2011) Application of a bioenergetics growth model for European anchovy (Engraulis encrasicolus) linked with a lower trophic level ecosystem model. Hydrobiologia 670:141-163

R Development Core Team (2008) R: a language and environment for statistical computing. R Foundation for Statistical Computing, Vienna. www.rproject.org

Rhode SC, Pawlowski M, Tollrian R (2001) The impact of ultraviolet radiation on the vertical distribution of zooplankton of the genus Daphnia. Nature 412:69-72

Scalabrin C, Diner N, Weill A, Hillion A, Mouchot MC (1996) Narrowband acoustic identification of monospecific fish shoals. ICES J Mar Sci 53:181-188

Simmonds EJ, MacLennan DN (2005) Fisheries acoustics: theory and practice, 2nd edn. Blackwell Science, Oxford

> Somarakis S, Drakopoulos P, Filippou V (2002) Distribution and abundance of larval fish in the northern Aegean Sea - eastern Mediterranean - in relation to early summer oceanographic conditions. J Plankton Res 24: 339-358

Soria M, Bahri T, Gerlotto F (2003) Effect of external factors (environment and survey vessel) on fish school characteristics observed by echosounder and multibeam sonar in the Mediterranean Sea. Aquat Living Resour 16: $145-157$

Tudela S, Palomera I (1997) Trophic ecology of the European anchovy Engraulis encrasicolus in the Catalan Sea (northwest Mediterranean). Mar Ecol Prog Ser 160: 121-134

Uriarte A, Prouzet P, Villamor B (1996) Bay of Biscay and Ibero Atlantic anchovy populations and their fisheries. Sci Mar 60(Suppl. 2):237-255

Wood SN (2006) Generalized additive models: an introduction with R. Chapman \& Hall, London

> Zwolinski J, Morais A, Marques V, Stratoudakis Y, Fernandes PG (2007) Diel variation in the vertical distribution and schooling behaviour of sardine (Sardina pilchardus) off Portugal. ICES J Mar Sci 64:963-9726

Submitted: February 9, 2011; Accepted: October 20, 2011

Proofs received from author(s): January 20, 2012 